\title{
High Flow Nasal Cannula Assisted Tracheostomy for Securing Airways in Patients with Acute Respiratory Distress Induced by Glottic Cancer
}

\author{
Seung Woo Hong (iD) and Dong Kun Lee (iD) \\ Department of Otolaryngology-Head and Neck Surgery, Dong-A University College of Medicine, Busan, Korea
}

급성 호흡곤란이 발생한 성문암 환자에서 기도 확보를 위한 고유량 비강 캐뉼라 보조 기관절개술

홍승우, 이동근

동아대학교 의과대학 이비인후-두경부외과학교실

Tracheostomy is considered as a first treatment, when oral intubation seems to be difficult in patient who present severe upper airway obstruction. Generally, tracheostomy is performed in supine position. But if airway obstruction is severe enough to cause dyspnea, low oxygen saturation and inability to maintain supine position, tracheostomy should be performed in sitting position. The authors report a case of successful tracheostomy using high flow nasal cannula which help to maintain stable oxygen saturation and respiration in patients with laryngeal cancer.

Keywords Airway obstruction; Tracheostomy; High flow nasal cannula; Laryngeal cancer.

\section{서 론}

기관절개술(tracheostomy)은 상기도 호흡 부전이 있을 때 기도폐쇄 부위를 우회하거 나, 기도 내 분비물의 제거 또는 기계적인 인공 환기를 위한 목적으로 시행된다. 때로는 심한 상기도 폐쇄로 인해 환자가 눕지도 못할 만큼 급성 호흡곤란이 발생하면 기도 삽 관이나 기관절개술이 실패할 가능성이 높다. 대체 방법으로 환자를 좌위로 하여 기관 절개술을 시행하거나, 윤상갑상막절개술을 응급으로 시행한 후 다시 기관절개술로 전 환할 수도 있다. 좌위로 기관절개술을 하면 노출이 좋지 않아 위험성이 있고, 응급 윤 상갑상막절개술을 시행한 경우 기관절개술보다 높은 위치에서 기도 확보 및 캐뉼라가 고정되므로 갑상 연골 및 진성대의 손상으로 인한 음성변화 및 기도협착이 기관절개술 보다 잘 발생할 수 있으며, 창상의 종양 오염과 같은 위험성이 있다. 저자들은 고용량 산소를 투여해도 앙와위를 취할 수 없을 정도로 심한 급성 호흡곤란이 발생한 진행성 후두암 환자에서 진정제 투여 없이 호흡 및 기도 유지를 위해 고유량 비강 캐뉼라 (high-flow nasal cannula: Fisher \& Paykel Healthcare Limited, Panmure, Auckland, New Zealand)를 적용하여 안정적인 산소포화도를 유지하면서 정상적인 앙와위

\footnotetext{
Received February 8, 2020

Revised March 17, 2020

Accepted April 1, 2020
}

\section{Corresponding Author} Dong Kun Lee, MD, PhD Department of OtolaryngologyHead and Neck Surgery, Dong-A University College of Medicine, 26 Daesingongwon-ro, Seo-gu, Busan 49201, Korea

Tel +82-51-240-5428

Fax+82-51-253-0712

E-mail chaos001@hanmail.net

\section{ORCID iDs}

Seung Woo Hong (D)

https://orcid.org/0000-0001-9198-4268 Dong Kun Lee (D) https://orcid.org/0000-0002-7296-1420

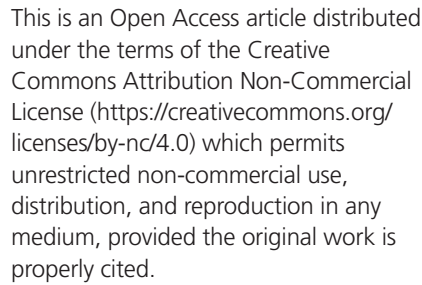

This is an Open Access article distributed under the terms of the Creative Commons Attribution Non-Commercial License (https://creativecommons.org/ licenses/by-nc/4.0) which permits unrestricted non-commercial use, distribution, and reproduction in any medium, provided the original work is properly cited. 
에서 성공적인 기관절개술을 시행하여 문헌 고찰과 함께 보 고하는 바이다.

\section{증 례}

81세 남자 환자가 1년 5개월 전 쉰 목소리가 발생하여 컴 퓨터단층촬영에서 성문암을 진단받았으나 치료 거부 후 지 내던 중 병원 방문 4일 전 발생한 악화되는 호흡곤란으로 구 급차를 이용하여 응급실로 내원하였다. 환자는 목소리가 전 혀 나오지 않았고 양측 폐에서 천명음(stridor)이 들렸다. 과 거력으로 22 년 전 거미막하출혈로 혈관내색전술을 시행한 적이 있다. 산소포화도는 구급대원이 환자에게 도착했을 때

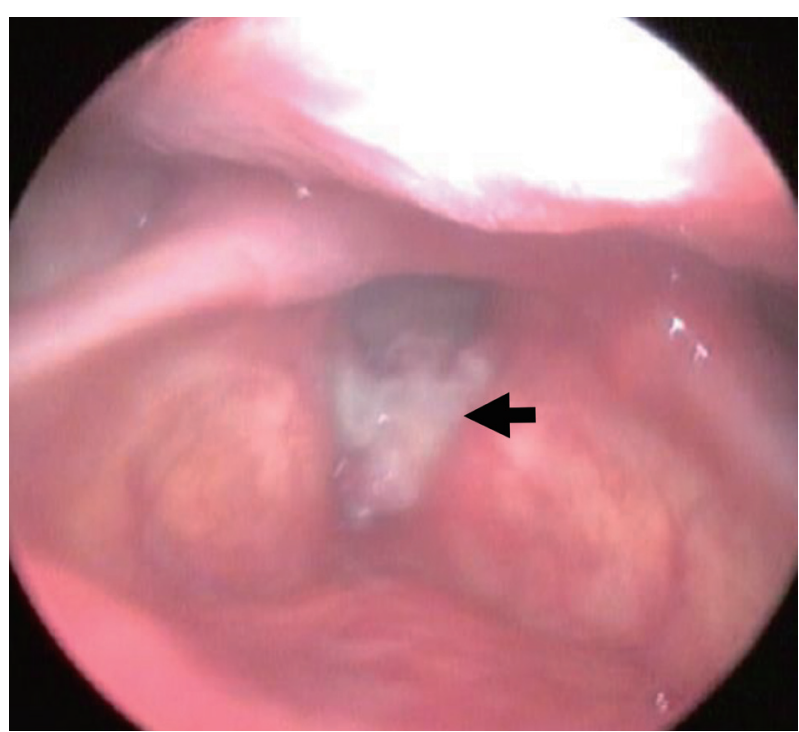

Fig. 1. Laryngoscopic exam of larynx. Shows large ulcerative mass involving the left vocal cord with narrowed posterior glottis gap (arrow).
$92 \%$ 로 측정되었고, 이후 비강 캐뉼라로 $3 \mathrm{~L} / \mathrm{min}$ 의 산소를 공급했다. 응급실 내원 후 $4 \mathrm{~L} / \mathrm{min}$ 로 공급한 채로 산소포화 도는 $100 \%$ 로 측정되었고, 동맥혈가스검사에서 산소 분압은 $60.2 \mathrm{~mm} \mathrm{Hg}$, 이산화탄소 분압은 $36.3 \mathrm{~mm} \mathrm{Hg}$, 산소포화도 는 $92.5 \%$ 로 측정되었다.

후두내시경검사에서 좌측 성문의 종괴가 앞쪽부터 뒤쪽까 지 모두 막고 있었으며 후성문 공간은 2 3 mm 정도만 열려 있었고 종괴로 인한 좌측 성대 마비가 관찰되었다(Fig. 1). 성 문암의 진행 정도와 상기도 폐쇄 정도를 평가하기 위해 경부 측면 단순 촬영을 시행하였고, 갑상연골 부근에 기도 폐쇄가 관찰되었다(Fig. 2A). 경부컴퓨터단층촬영검사에서 성문부에 불균질하게 조영이 증강된 종괴가 성문하 $2 \mathrm{~mm}$ 까지 침윤되 었고, 성문은 $3 \mathrm{~mm}$ 로 좁아져 있었다(Fig. $2 \mathrm{~B}, \mathrm{C}$ ). 염증의 정 도를 평가하기 위해 시행한 혈액검사에서 백혈구 $11,560 / \mu \mathrm{L}$, 호중구 $88.6 \%, \mathrm{C}$ 반응단백질 $4.44 \mathrm{mg} / \mathrm{dL}$ 로 증가된 소견이 보 였고, 적혈구 침강 속도는 $20 \mathrm{~mm} / \mathrm{h}$ 로 정상 소견이 보였다.

환자는 비강으로 $4 \mathrm{~L} / \mathrm{min}$ 의 산소 공급을 받으면서 앉은 자 세에서는 산소포화도가 98 100\% 유지되었으나 경한 호흡 곤란을 호소하고 있었고, 앙와위에서는 호흡곤란이 심해지 고 산소포화도가 88 92\%까지 감소할 정도로 호흡곤란이 있었다. 큰 후두 종괴와 부종으로 기도 폐쇄가 임박하여 더 악화될 위험성이 매우 높아서 응급으로 기도 확보가 필요하 다고 판단되었다. 앙와위에서는 호흡곤란이 악화되기 때문 에 일반적인 방법으로 기관 절개술은 불가능하였다.

저자들은 고유량 비강 캐뉼라를 통해 양압으로 산소를 공 급하면 이처럼 기도가 아주 좁은 상태에서는 산소 공급을 더 원활히 보조하여 산소포화도를 더 안정적으로 유지시키 면서 앙와위에서도 기관절개술을 시행할 수도 있다고 생각 하였다. 만약 이 방법이 불가능하면 다음 방법으로 윤상갑상
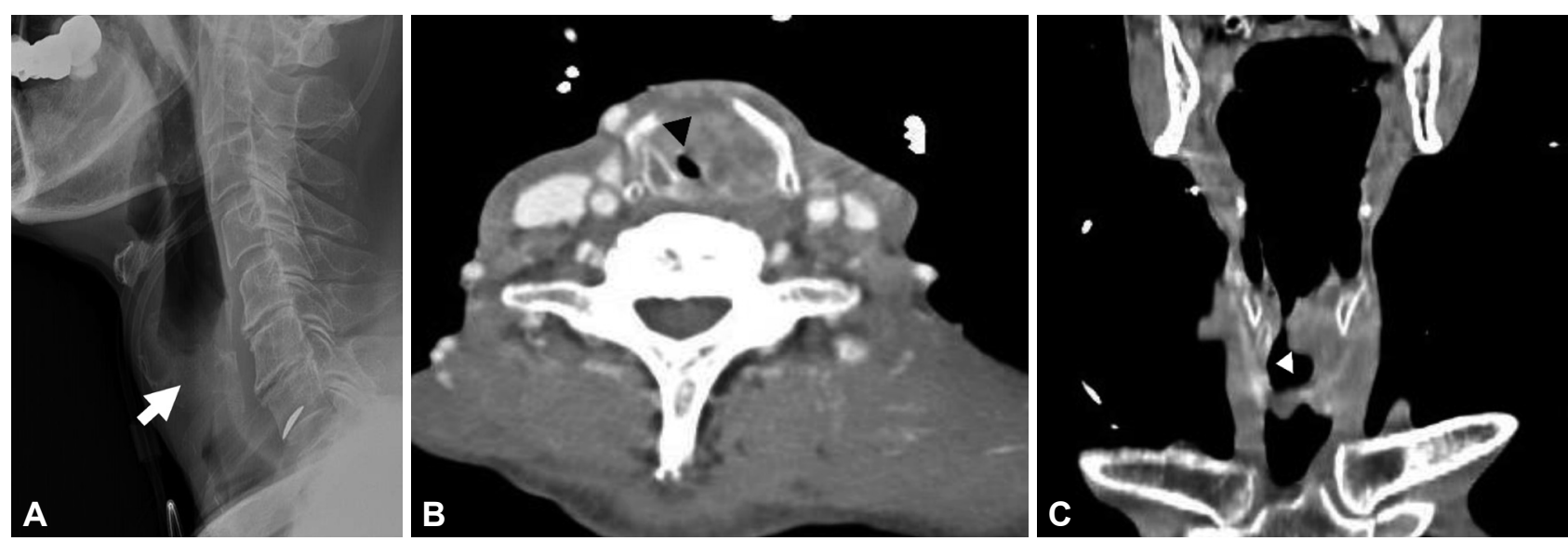

Fig. 2. Neck radiologic exam. Shows simple neck radiography showing narrow airway at the thyroid cartilage area (arrow) (A). Shows axial enhanced image of neck computed tomography showing heterogeneous enhancing the left vocal mass with narrowed airway (arrow head) (B). Shows coronal enhanced image of neck computed tomography showing large glottis mass invading the supraglottis, the paraglottis and the subglottis (arrow head) (C). 
막절개술 후 다시 기관절개술로 전환하기로 계획하였다.

수술 2시간 전 비강 캐뉼라를 통한 $4 \mathrm{~L} / \mathrm{min}$ 의 고유량 산 소요법을 통한 유량 $40 \mathrm{~L}$, 흡입기 산소농도 $40 \%$ 로 공급한 후 환자가 호흡곤란이나 저산소혈증 없이 앙와위를 유지할 수 있음을 미리 확인하였다. 수술 25분 전, 저산소증을 예방 하기 위해 환자에게 공급 가능한 최고 용량인 유량 $60 \mathrm{~L}$, 흡 입기산소농도 $90 \%$ 로 공급하였고, 환자는 진정제 투여 없이 앙와위에서 호흡곤란을 호소하지 않았고, 산소포화도 $100 \%$ 로 유지되어 일반적인 방법으로 성공적인 기관절개술을 시 행하였다. 수술자도 환자의 안정적인 생체 징후 및 수술 자세 유지가 가능했기 때문에 수술 중 특별한 어려움 없이 마쳤고 수술 후 특별한 합병증은 없었다. 수술 후 후두암 치료를 권 유하였으나 거부하고 입원하여 경과 관찰 중에 요양병원으로 전원 하였다.

\section{고 찰}

후두 종괴나 염증으로 기도 폐쇄가 발생할 경우 기도 확보 를 위한 경구강 기도 삽관은 출혈이나 좁은 시야로 인해 실 패할 가능성이 높고 반복적인 삽관 시도는 부종과 출혈로 인 해 호흡 정지(respiratory arrest)까지 초래할 수 있다. 본 증 례와 같이 후두 폐쇄가 심한 경우에 근육이완제 또는 진정제 를 투여하여 기도 삽관을 시도하는 것은 약물 투여 시점과 삽관이 이루어지는 시간 사이에 기도 폐쇄가 더 악화되어 환 자에게 호흡 정지가 발생할 가능성이 매우 높아서 환자가 사 망에 이를 수 있으므로 기관 삽관은 지양된다. 기도 삽관 외 에 기도를 확보하는 방법으로는 윤상갑상막절개술, 경피적 확장 기관 절개술, 그리고 전통적인 기관절개술 등이 있다. ${ }^{1)}$ 윤상갑상막절개술은 응급으로 기도를 우선 확보할 수 있으 나 성문하협착, 갑상연골과 윤상연골의 손상 등의 합병증 때 문에 수술 이후 72 시간 이내에 진정제를 투여 후 반드시 기 관절개술을 다시 시행해야 한다는 단점이 있다. ${ }^{2)}$ 경피적 확 장 기관 절개술은 이전에 기관절개술을 받은 적이 있는 경 우, 목의 기형이 있거나 해부학적으로 시술이 어려운 경우, 교정이 어려운 혈액응고 장애가 있는 경우, 그리고 응급으로 시행해야 할 경우 등은 시술 금기이다. ${ }^{3)}$

일반적 기관절개술은 앙와위에서 시행되는데 환자의 호흡 곤란이 심해서 앉을 수 없다면 좌위에서 시행해야 하고, 환 자의 불충분한 경부 신전으로 인해 기관의 노출과 시야가 좋 지 않다. 앙와위에서는 기관이 수평이지만 좌위는 기관이 비 스듬히 위치하기 때문에 시야가 쉽게 왜곡되고 계획된 기관 절개공 보다 높거나 낮은 부위로 접근할 수도 있다. 수술 시 간도 길어지게 되며, 언제든지 후두 폐쇄가 악화되어 호흡 정

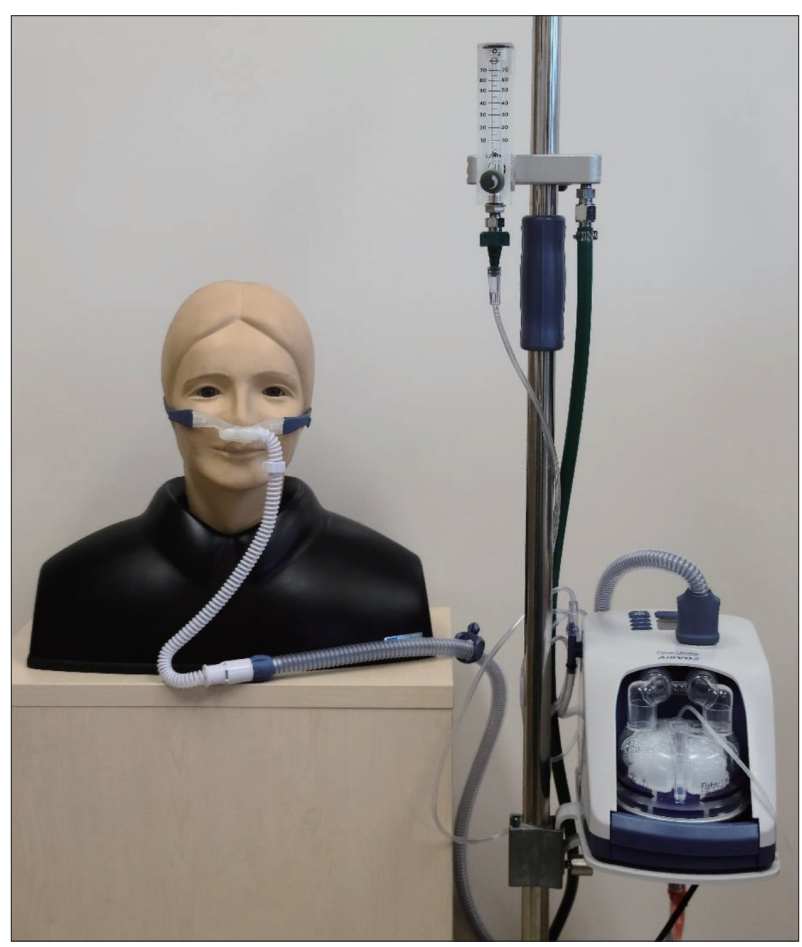

Fig. 3. High flow nasal cannula. Shows two-in-one equipment with flow generator and nasal cannula.

지가 될 위험성도 있어 시술의 난이도 높아지며 시술자에게 부담이 된다.

가능한 앙와위를 유지하면서 산소공급이 원활하게 이루어 지는 방법이 필요하며 고유량 비강 캐뉼라가 그 대안이 될 수 있다. 고유량 비강 캐뉼라 요법은 직경이 더 굵고 긴 비강 캐뉼라를 사용하여 최적으로 가온 가습된 산소를 제공하는 산소 요법이다(Fig. 3). 비인두에 지속적인 고유량 산소를 공 급하여 비인두의 잔존 이산화탄소를 제거하고 산소의 저장 소를 형성하며 이산화탄소 재호흡을 감소시켜 해부학적 사 강(dead space)을 감소시키는 효과를 통해 환자의 호흡을 보조할 수 있다. 또한 마스크 환기와 비교하여 실내 공기 (room air)로 인한 산소 농도 희석을 최소화할 수 있어 정확 한 산소 전달이 가능하다. 고유량 비강 캐뉼라 요법은 가온 가습된 산소를 제공하여 기도 건조를 예방하고 기도 내 점 액 섬모 운동을 촉진하여 호흡기계 감염을 감소시키는 장점 도 존재한다.

고유량 비강 캐뉼라를 사용하여 기관절개술을 성공한 증 례 보고가 있으나 술 중 진정을 시행하였고 술 중 완전 기도 폐쇄와 저산소증의 합병증이 있었으나, 본 증례에서는 진정 없이 일반적인 앙와위에서 합병증 없이 시행한 점이 차이라 할 수 있다.,5) 고유량 비강 캐뉼라를 사용할 경우 산소공급 유지에 실패하여 저산소증을 유발할 수 있으므로 주의가 필 요하여 술 중 산소포화도에 대한 모니터링이 필요하다. 
또 다른 합병증으로 기도 발화가 있다. 고농도의 산소가 수 술 부위로 흘러 들어가면 전기를 이용한 수술 도구나 레이저 가 작동될 때 발화를 일으킬 수 있다. 레이저를 이용하는 두 경부 수술에서는 특히 유의하여야 한다.) 따라서 고유량 비 강 캐뉼라를 통한 산소공급법은 수술 시간이 길지 않거나 간 단한 시술에서 전신마취 대신 일시적 기도 유지 목적으로 사 용 가능하며, 저산소증은 전신마취나 진정 약물이 투여함으 로서 발생하기 때문에 주의가 필요하다. 저자들의 증례에서 는 응급 기관절개술이 필요하였고, 기도 폐쇄가 환자가 누울 수 없을 정도로 심했지만, 진정제 투여 없이 고유량 비강 캐 뉼라를 통해 안정적인 수술 시간과 환자 자세 유지를 가능하 게 하여 성공적인 기관절개술이 가능하였고 상기도 폐쇄로 응 급 기관절개술이 필요한 경우 산소 공급을 보다 원활히 하기 위한 방법으로 비강 캐뉼라가 도움이 될 것으로 생각한다.

중심 단어: 기도 폐쇄, 기관절개술, 고유량 비강 캐뉼라, 후 두암.

Acknowledgments

This study was supported by research funds from Dong-A University.

Conflicts of Interest

The authors have no financial conflicts of interest.

\section{Authors' Contribution}

Conceptualization: Dong Kun Lee. Data curation: Seung Woo Hong. Formal analysis: Dong Kun Lee. Investigation: Seung Woo Hong. Methodology: Dong Kun Lee. Project administration: Dong Kun Lee. Resources: Seung Woo Hong. Software: Seung Woo Hong. Supervision: Dong Kun Lee. Validation: Dong Kun Lee. Visualization: Seung Woo Hong. Writing_original draft: Seung Woo Hong. Writing_review\&editing: Dong Kun Lee.

\section{REFERENCES}

1. Shokri T, Goldenberg D. Emergency operative airway techniques. Oper Tech Otolayngol Head Neck Surg 2017;28(4):252-7.

2. Hsiao J, Pacheco-Fowler V. Videos in clinical medicine. Cricothyroidotomy. N Engl J Med 2008;358(22):e25.

3. Klotz R, Probst P, Deininger M, Klaiber U, Grummich K, Diener MK, et al. Percutaneous versus surgical strategy for tracheostomy: a systematic review and meta-analysis of perioperative and postoperative complications. Langenbecks Arch Surg 2018;403(2):137-49.

4. Ffrench-O'Carroll R, Fitzpatrick K, Jonker WR, Choo M, Tujjar O. Maintaining oxygenation with high-flow nasal cannula during emergent awake surgical tracheostomy. Br J Anaesth 2017;118(6): 954-5.

5. Desai N, Fowler A. Use of transnasal humidified rapid-insufflation ventilatory exchange for emergent surgical tracheostomy: a case report. A A Case Rep 2017;9(9):268-70.

6. Onwochei D, El-Boghdadly K, Oakley R, Ahmad I. Intra-oral ignition of monopolar diathermy during transnasal humidified rapidinsufflation ventilatory exchange (THRIVE). Anaesthesia 2017;72 (6):781-3. 